\title{
Fichte e Schelling e o Debate Inaugural do Idalismo Transcendental
}

Luciano Carlos Utteich

\section{CpenEdition}

Journals

Edição electrónica

URL: http://journals.openedition.org/ref/258

DOI: $10.4000 /$ ref.258

ISSN: 2258-014X

Editora

EuroPhilosophie Editions

Refêrencia eletrónica

Luciano Carlos Utteich, «Fichte e Schelling e o Debate Inaugural do Idalismo Transcendental », Revista de Estud(i)os sobre Fichte [Online], 5 | 2012, posto online no dia 01 janeiro 2013, consultado o 08 setembro 2020. URL : http://journals.openedition.org/ref/258; DOI : https://doi.org/10.4000/ref.258

Este documento foi criado de forma automática no dia 8 setembro 2020

(C) EuroPhilosophie 


\title{
Fichte e Schelling e o Debate Inaugural do Idalismo Transcendental
}

\author{
Luciano Carlos Utteich
}

\section{Idealismo Prático ou Dogmatismo Perfeito}

1 Nos dois estudos de Fichte, introdutórios à Grundlage der gesammten Wissenschaftslehre (Fundação completa da Doutrina da Ciência, 1794), chamados Erste Einleitung in die Wissenschaftslehre (Primeira Introdução à Doutrina da Ciência, 1797) e Zweite Einleitungung in die Wissenschaftslehre (Segunda Introdução à Doutrina da Ciência, 1797-98), ele apresentou o debate através do qual funda o Idealismo transcendental, partindo da confrontação entre as duas escolas teóricas que se opuseram desde o advento da Crítica da razão pura de Kant, o Dogmatismo e o Idealismo. Na tentativa de conciliar uma das duas escolas herdeiras de Kant com os resultados obtidos na fundação da Doutrina da Ciência, Fichte estabeleceu o Idealismo transcendental como a perspectiva complementar ao estágio negativo da razão pura kantiana: só pela Doutrina da Ciência, como prerrogativa da filosofia, se demonstra o fundamento de todas as representações e a possibilidade de fazer coincidir o pensante e o pensado, vindo a ser nisso superado o estágio kantiano da razão, sugerido pelo Ich denke, do mero "acompanhar as minhas representações" ${ }^{1}$, em favor - agora - do resgate da origem das representações no sujeito, para considerá-las todas como fundadas na atividade originária do sujeito (Ich bin). Entretanto, a possibilidade de o Idealismo transcendental fundar o sistema da razão, fornecer a base do distanciamento crítico presente na razão kantiana e considerar o pensamento do ponto de vista de um olhar complementar graças ao fundamento originário da "espontaneidade" do pensamento, assentada numa atividade originária, não-sensível, mas inteligível da razão, foi demonstrada também nos estudos de Schelling. Buscando fundar o sistema na dimensão inteligível da razão, a perspectiva sistemática postulada dever-se-ia mostrar por isso como idêntica às condições exigidas pelo Idealismo para fundar-se de modo filosófico e transcendental, na superação da sobrepujança histórica 
das escolas existentes. Depreender-se-á daí que o modo pelo qual Fichte e Schelling apresentaram o fundamento do Idealismo transcendental não tenha conclusivamente assentado sobre o mesmo elemento teórico nem mesma figura da espontaneidade. Para Fichte a consciência de si tem de ser concebida como originária, dependente do sujeito (Ich bin), e não de uma coisa (ou ser). No texto fundacional de 1794 distinguira entre ser absoluto e existência efetiva, a fim de assinalar esse ponto, considerado por ele como o verdadeiramente originário; e então disse: "A doutrina da ciência distingue cuidadosamente o ser absoluto e a existência efetiva, e coloca o primeiro meramente como fundamento para explicar a última"2. Nos estudos das duas Introduções, Fichte assinalou em vários momentos os modos de refutar as exigências do sistema do dogmático, cercando e contornando os limites empíricos esboçados neste pretenso sistema, mediante a ênfase colocada no caráter crítico proporcionado pela perspectiva Idealista transcendental (Idealismo Absoluto), que discrimina duas noções de ser, a noção de ser empregado pelo sistema do Dogmático (que se refere à coisa ou coisa em si) e a noção de ser para si empregado pelo Idealismo Absoluto, que entende como objetiva a necessidade da Inteligência de reconhecer como ato válido só para-si mesma o ato de referir as representações presentes na consciência, independente de quais forem os motivadores das representações. Assim, enquanto atributo pertencente a um próprio modo de atuar da Inteligência, que consiste em voltar-se-para-si-mesmo sempre, Fichte enfatiza o duplo ato referencial ${ }^{3}$ a que a Doutrina da Ciência (ou o Idealismo transcendental por ela compreendido) sempre deve se ater, dizendo: "Eu mesmo (...) sou para mim um objeto cuja natureza depende - numas condições precisas - só da Inteligência, e cuja existência, ao contrário, deve sempre se pressupor" ${ }^{4}$. Nas palavras do texto fundacional de 1794, Fichte explicita: "O Eu é dependente segundo sua existência, mas é pura e simplesmente independente nas determinações dessa sua

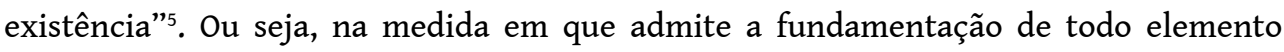
subjetivo como capaz de ser explicado pela Inteligência $(\mathrm{Eu})$, ele considera de outro modo, de modo diferente, a capacidade explicativa referida a todo elemento objetivo, por parte da Inteligência (Eu). Diz: “A presença daquilo que deve ser subjetivo poderia (...) ser explicada pelo pôr do Eu pura e simplesmente por si mesmo, mas não a presença daquilo que deve ser objetivo, pois este está pura e simplesmente não posto pelo pôr do Eu"6. Para Fichte é suficiente elevar todos os condicionamentos à série da reflexão na estrutura autoreflexiva do pensamento. Para ele esse exercício deve ser tornado habitual porque fundado na "possibilidade de dirigir conforme o dever sua atenção a algo, e desviá-la de outro algo, [possibilidade] sem a qual nenhuma moral é possível"7. Os atos necessários da Inteligência são co-constituídos com o princípio da razão que antecipa o fim moral desde a espontaneidade originária, como expressão de um impulso da faculdade prática do Eu à realidade, como esforço prático, diz Fichte, "por modificar (...) a força oposta (...) independente do Eu segundo seu ser e sua determinação"s que, por outro lado, entretanto, pré-existe pelo fato de que a força oposta existirá como "dependente da atividade ideal do Eu (...) [ou seja], ela só é para o Eu na medida em que é posto por ele e, fora disso, não é para o Eu"'. Ou ainda, como diz ele: "Apenas na medida em que é referido à faculdade prática do Eu, algo tem realidade independente; na medida em que é referido à [faculdade] teórica, esse algo está apreendido no $\mathrm{Eu}$, contido em sua esfera, submetido a suas leis de representação"10. Afinal, como poderia, por fim, "ser referido à faculdade prática, senão pela [faculdade] teórica, e como pode tornar-se um objeto da faculdade teórica, senão mediante a [faculdade] prática?"11 Mas a prerrogativa fichtiana de resgate da origem das 
representações no sujeito, por isso, pela sua vinculação só à consciência enquanto movimento autoreflexivo (voltar-se-a-si-mesmo) e por ser dependente em certo sentido de uma existência (a ela inexplicável), contrastará com a prerrogativa schellinguiana de considerar para origem das representações tanto o elemento subjetivo como o objetivo, atividades originárias a serem consideradas desde duas perspectivas - nomeadas posteriormente, nos textos seguintes schellinguianos. Em virtude disso Schelling estende a abordagem fundadora do Idealismo transcendental para incluir sob ela a filosofia da natureza ${ }^{12}$. Assim, para ele doravante tem de ser distinguido, diz, “[...] entre o ser (Wesen), na medida em que existe, e o ser na medida em que é mero fundamento (Grund) da existência (Existenz). [Já que] Esta distinção é tão antiga como a primeira apresentação científica desta filosofia" ${ }^{13}$.

\section{O Idealismo transcendental através da Crítica da razão pura}

2 Os primeiros rumores da ampliação da fundação da doutrina do Idealismo podem ser percebidos no texto Philosophischen Briefen über Dogmatismus und Kritizismus ${ }^{14}$ (Cartas filosóficas sobre o Dogmatismo e o Criticismo), que adota como perspectiva decisiva a de que subjaz, prévia à toda cisão e mesmo a toda síntese teórica e prática, um "ser originário" enquanto um princípio originário como condição vital que se subtrai a toda regra. Desde este ponto de partida se pode identificar no assunto introduzido pelo texto Cartas Filosóficas a tematização de um princípio da razão (princípio da causalidade em geral ou da conformidade à razão) que é primeiro em relação tanto ao subjetivo como ao objetivo. Pois, diz Schelling, se "quanto mais intermediários eu coloco entre ele [mundo] e mim [Eu], tanto mais limitada é a minha intuição dele", então isso por si só já colocaria "afastado de mim (...) o mundo"15. Unicamente em vista disso eu teria, então, de colocar "um ser superior" entre Eu e o mundo, como que para considerar a necessidade de "um guardião do mundo para mantê-lo [mundo] em seus limites"16. Entretanto, um tal ser superior denotaria um conceito com significado imediatamente moral, do incondicionado obtido como conceito moral - e que foi inteiramente rechaçado pela nova tematização do incondicionado, trazida pelo texto Cartas. Isso se constituirá imediatamente, também, em um obstáculo, pois na medida em que a prerrogativa - de resgate da origem das representações - não nega o fato de que o aparato cognoscitivo humano "forma a matéria (...) de dentro para fora" ${ }^{17}$, o ato de colocar intermediários entre $\mathrm{Eu}$ e o mundo favorece unicamente o esmorecimento reflexivo do sujeito (esmorecimento embasado pelo amparo numa prova moral do incondicionado). Com efeito, o princípio interior constitutivo da matéria desde dentro para fora se vincula diretamente à intuição (Einsicht) intelectual do mundo, e é imprescindível a fim de se realizar "a unificação instantânea dos dois princípios conflitantes em nós"18, que permanece existente em função dessa unificação e dessa luta. Neste sentido, na medida em que toda tentativa de prova da existência de Deus, como um Deus moral, só consegue lançar mão sempre "apenas [de] uma outra representação antropomórfica", então já não haverá - nesse Deus moral - "nem um lado estético, nem um lado filosófico" ${ }^{19}$, pois faltaria demonstrar em que sentido pode aparecer nessa representação de Deus a noção do sublime (incondicionado, do ponto de vista estético). Schelling inaugura, no interior da doutrina do Idealismo transcendental, a tematização da Natureza ${ }^{20}$ - enquanto tematização do incondicionado ou da atividade 
originária do lado do objeto - como outro possível tema filosoficamente relevante e especial em relação ao conjunto de objetos fundados pelas atividades da razão transcendental. Assim, diz ele, se "a Filosofia tem que partir do absoluto" ${ }^{21}$, isso é porque o incondicionado aparecia ao Dogmatismo e ao Criticismo como inconcebível: "Até onde eu entendo, esse inconcebível é, tanto para o criticismo quanto para o dogmatismo, teoricamente insolúvel"22. Pois, diz Schelling, "se o sistema inteiro do criticismo fosse fundado única e exclusivamente na faculdade de conhecer, o fim último do criticismo, o de tornar livre a humanidade, não teria efetivamente sido alcançado" 23 . A questão é justamente essa: "o que se ganha com isso, quanto à questão teoricamente insolúvel" - a propósito do incondicionado como aquilo que está além da lei de identidade da razão teórica -, com o fato de que o criticismo pode "certamente provar a necessidade de proposições sintéticas para o domínio da experiência?" ${ }^{24}$ No dizer de Schelling, só "desatando o nó górdio (..) pode essa questão ser respondida" ${ }^{25}$, isto é, a própria questão deve ser suprimida. E isso significa: "uma tal solução dessa questão não pode mais ser teórica, mas se torna necessariamente prática" ${ }^{26}$. Ou seja, para responder essa questão "tenho de suprimir para mim os limites do mundo da experiência, tenho de deixar de ser um ser finito"; e na medida em que só "para a razão em geral vale a necessidade de se tornar [razão] prática - e não para uma razão determinada, aprisionada nos grilhões de um sistema isolado" ${ }^{27}$, não é pela recorrência aos postulados práticos que se alcança isso, pois pelos postulados só se é levado "a uma região onde não encontro terra firme, mas tenho de produzir essa terra, a fim de poder me firmar, depois, sobre ela, além dos limites do saber" ${ }^{28}$. Sem admissão de nenhum subterfúgio - como daqueles que fizeram o criticismo buscar num mundo absolutamente objetivo e num Deus moral a justificação para causas naturais, em face da fraqueza e cegueira da razão teórica ${ }^{29}$ - o dogmatismo perfeito exigirá do próprio ser originário que este admita uma objetividade absoluta. Isso significa: o ser originário é que deve explicar a necessidade de uma existência que é independente da lei (absolutos) ${ }^{30}$ - não cabendo mais conceder tal tarefa à mera índole da faculdade de conhecer. Segundo Schelling advém o "forte atrativo peculiar ao dogmatismo, pelo menos na medida em que ele não parte de abstrações ou de princípios mortos, mas (pelo menos em sua forma perfeita) de uma existência, que zomba de todas as nossas palavras e princípios mortos" ${ }^{31}$. Mas, isso era para ser entrevisto a partir da própria Crítica da razão pura, na medida em que ela tem apenas o status de um cânon da razão, e não de um sistema desenvolvido: ela é a condição dos sistemas - de dois deles - o criticismo e o dogmatismo ${ }^{32}$; e uma decorrência necessária do conceito de filosofia é que "não poderia haver, em geral, sistemas diferentes, se ao mesmo tempo não houvesse um domínio comum a todos eles" ${ }^{33}$. Se, por um lado, a Crítica estabeleceu o método dos postulados práticos para dois sistemas inteiramente opostos, por outro lado, era impossível a ela "ir além do mero método, e como ela devia atender a todos os sistemas, era-lhe impossível determinar o espírito próprio de cada sistema em sua singularidade" ${ }^{34}$. Pois, no dizer de Schelling, para o filósofo crítico "o mais concebível é: como nós determinamos tudo meramente pela lei da identidade. $\mathrm{E}$ o mais enigmático é: como nós podemos determinar ainda algo, para além dessa lei [da identidade]" 35 . Schelling encaminha a questão do seguinte modo: se Kant procurou garantir no princípio do $\mathrm{Eu}$ penso (Ich denke) uma unidade analítica (como identidade da consciência com as suas representações) e uma unidade sintética (como identidade da consciência consigo mesma), faltou encontrar um princípio que perpassasse a unidade analítica desde a unidade sintética ou perpassasse a unidade sintética desde a unidade 
analítica, isto é, faltou encontrar o primeiro e único verdadeiro fundamento de todas as sínteses, subjacente ao fornecido pela faculdade do entendimento (Verstand) às categorias (deduzidas no número de doze), como sínteses categoriais. Essas são as condições de uma síntese prévia ao sujeito e ao objeto, como unidade absoluta, incondicionada, anterior à unidade obtida pela síntese fornecida pelas categorias. Então, conclui Schelling: “Acredito mesmo ter encontrado, no próprio criticismo, a solução do enigma: porque esses dois sistemas [criticismo e dogmatismo] têm necessariamente de subsistir um ao lado do outro, porque, enquanto ainda existirem seres finitos, também tem de haver dois sistemas diretamente opostos entre si. [...] Porque, enfim, nenhum homem pode se convencer de um sistema qualquer a não ser, apenas, praticamente, isto é, por ter realizado um dos dois em si mesmo" ${ }^{36}$. Assim, o problema dos dois sistemas, que é o mesmo, exige ser solucionado praticamente. A fim de que isso seja possível, o sistema autenticamente absoluto, ao invés de ser um sistema que é objeto do saber, deve se tornar sempre somente objeto da liberdade. Numa terceira nuance, ladeada pelos extremos - de um lado pelo criticismo (prova moral da existência de Deus) e, do outro, pelo dogmatismo (dogmatismo forte ou dogmaticismo), o dogmatismo se levanta da oposição entre as duas escolas filosóficas históricas, na designação de um Dogmatismo perfeito: "Quanto a mim, acredito que há um sistema do dogmatismo, assim como há um sistema do criticismo" ${ }^{37}$. Mas, Schelling adverte: "Nenhum de nós queira fazer passar seu sistema dogmático [perfeito] por um sistema do criticismo, por ter tomado emprestado da Crítica da razão pura a norma para construí-lo" ${ }^{38}$. Como fundamento e condição geral imprescindível para obter as formas puras do pensar em geral, tem de pertencer portanto esse primeiro e único fundamento, o incondicionado, à razão em geral (Vernunft), e não à razão determinada (Verstand). Desde aqui a investigação schellinguiana exige partir do conceito do incondicionado (das Unbedingte), visto que à base da existência do mundo da experiência sempre subsistirá um propósito superior, o de sair da esfera mesma da experiência e alçar-se sobre ela, até ao incondicionado, como o domínio verdadeiramente legítimo desde o qual o homem se constitui enquanto razão. Logo, a necessidade de rever a efetividade do dogmatismo, através do próprio criticismo, como uma atividade dogmática positiva, se vislumbra na forma de uma antecipação entreaberta ${ }^{39}$, na qual Schelling julga haver descoberto o sistema definitivo da filosofia transcendental, ao qual nenhum modelo teórico conseguirá refutar, praticamente: "Estou firmemente convencido de que, mesmo quando chega à sua perfeição, o sistema do criticismo não pode refutar teoricamente o dogmatismo. Certamente, este é demolido na filosofia teórica, mas apenas para se reerguer com uma potência ainda maior" ${ }^{\prime 4}$, a saber, na esfera da efetividade sistemática ou prática. Isto porque, na verdade, o dogmatismo refutado negativamente pelo criticismo cai na classe daquele modelo designado por dogmaticismo. Tem-se aqui, então, a apresentação daquela nuance ${ }^{41}$ que torna clara a perspectiva schellinguiana, através da qual se resgata um acréscimo de sentido ao termo dogmatismo, que Kant não tomara em apreço: ela se refere ao realce concedido à ideia da Filosofia sempre primeiramente como filosofia da natureza. E assim a doutrina, denominada Idealismo transcendental, que recebera na Crítica da razão pura um tratamento monocromático sob a ênfase da dimensão fenomênica e sensível, do mundo e da natureza, desde a qual tinham sido vinculados os domínios da sensibilidade e do entendimento, como radicalmente distintos, na ênfase e no esclarecimento, por fim, de que "[...] tudo o que se intui no espaço e no tempo e, por conseguinte, todos os objetos de uma experiência possível para nós, são apenas 
fenômenos, isto é, meras representações que, tal como as representamos enquanto seres extensos ou séries de mudanças, não têm fora dos nossos pensamentos existência fundamentada em si. A esta doutrina chamo eu idealismo transcendental" ${ }^{42}$, notoriamente aparece discriminando menos os aspectos inteligíveis que os aspectos empíricos envolvidos no ato constitutivo do conhecimento. Com isso Kant privilegiara a aplicação das categorias à natureza (razão teórica) do ponto de vista constitutivo. Todavia, a esta altura já havia fundado, no texto da Crítica da razão pura, a diferença e o uso, com sentidos distintos, dos objetos possíveis em fenômeno e noumeno ${ }^{43}$, possibilitando relativizar os resultados do Entendimento, em vista de um desdobramento mais coerente partindo exclusivamente do domínio da Razão.

\section{Conclusão}

3 Ao lado do debate acerca do Älteste Systemprogramm des Deutschen Idealismus (O mais antigo Programa de Sistema do Idealismo alemão) ${ }^{44}$, o debate sobre a fundação do Idealismo Transcendental, doutrina inicialmente elaborada por Kant e capitaneada por Fichte e Schelling, coloca-se como decisivo, pois aquele não prescinde das bases fundadoras implantadas pelo Idealismo transcendental, este último fica-lhe atrás no sentido de que lhe precedeu e condicionou o desenvolvimento posterior nas suas versões Objetiva e Absoluta. Por ter terem adotado estratégias distintas na apresentação da perspectiva incondicionada e racional fundada do ponto de vista sistemático, mostrou-se neles preservada a autêntica explicação filosófica transcendental, que não pode prescindir do atuar ou da capacidade inteligível para organizar a própria experiência, seja do ponto de vista sensível, seja do ponto de vista inteligível. Para Fichte e para Schelling a questão motivada pelo texto kantiano atendeu a uma espécie de corrida de bastão de revezamento da questão do sistema do Idealismo, motivando apropriar-se daquela doutrina como lugar inicial de sistema da filosofia, trazendo ao debate a questão da constituição e desenvolvimento do que devia ser entendido, num sentido depurado, como a única via ou "o único modo existente em filosofia de pensar conforme o dever" ${ }^{45}$, isto é, de conceder ao pensamento a amplitude de atividades que lhe cabe por direito, enquanto o domínio completo de atividades da razão (Vernunft) tem de poder ser todo ele por primeiro pensado para considerá-la, então, como fundada de modo transcendental, neutralizam as perspectivas empíricas e históricas.

\section{NOTAS}

1. KrV B 131-132 (Crítica da razão pura, tr. M. P. DOS SANTOS e A. F. MORUjÃo, Lisboa: Calouste Gulbenkian, 1990 [= CrP], p. 131.

2. GA I/2, 419 GWL Fn. (A Doutrina da Ciência de 1794, tr.: TORRES FILHo, R. R., São Paulo: Abril Cultural, 1972 [= DCp], p. 149, nota de rodapé. 
3. Nesta medida pode-se reconhecer aqui, nesse duplo ato referencial, na verdade, dois atos autoreferenciais: um ato autoreferencial (desde a consciência que parte da consciência e volta para si mesma, e neste sentido trata das determinações) e um ato autoreferencial (que vai desde a consciência para a existência e retorna para a consciência, e neste sentido mantém a existência como um fato bruto). Para uma exposição detida do duplo sentido no significado da palavra pôr (setzen), Cfr. GA I/2, 325 GWL (DCp, p. 92).

4. GA I/4, $190 \mathrm{EE}$.

5. GA I/2, 411 GWL (DCp, p. 150).

6. GA I/2, 354 GWL (DCp, p. 110).

7. GA I/2, 424 GWL (DCP, p. 158).

8. GA I/2, 413 GWL (DCp, p. 151).

9. Ibidem.

10. Ibidem.

11. Ibidem.

12. Como continuação do movimento de dupla face à propósito do trabalho realizado na perspectiva dos dois lados da razão, Schelling procederá desenvolvendo a discursividade da razão a fim de demonstrar um caráter regular na demonstração (construção) dos conceitos. Então, a questão passa a ser para ele, de modo resumido aqui, justamente a seguinte: "Como podem ser pensadas as representações regendo os objetos e, ao mesmo tempo, ser pensados os objetos regendo as representações?" (System des transzendentalen Idealismus, 1800 - Sistema del idealismo transcendental, tr. J. R. de R. CHACón \& V. L. DOMINGUEZ, Barcelona: Anthropos, 1988, p. 348 [=SIT]). A partir disso o Sistema do Idealismo distingue entre a dimensão transcendental (razão técnicoteórica) e a dimensão prática, devendo conciliá-las, como conciliação da dimensão técnicoconstitutiva da natureza e da dimensão prática da ação humana.

13. SSW I/7, 366 Fn. (A Essência da Liberdade Humana. Investigações filosóficas sobre a essência da liberdade humana e das questões conexas. Tr. DE SÁ CAVALCANTE, M. C., São Paulo: Vozes, 1991 [= IFELH], p. 38 nota de rodapé. Igualmente pode-se confrontar SSW IV, 198, no texto Darstellung meines System der Philosophie (1801) (Exposição do meu sistema de Filosofia), publicado em 1801 na Zeitschrift für spekulative Physik, fundada por Schelling em 1798 para divulgar a nova filosofia da natureza. Servimo-nos da edição de M. Durner, Zeitschrift für spekulative Physik. Bd. II, Zw. Hft. Hamburg: Meiner, 2001, 329-459.

14. Publicado inicialmente no Philosophisches Journal em 1795 e posteriormente recolhidas no primeiro volume dos Escritos Filosóficos (1809).

15. F.W.J. SCHELling, Philosophischen Briefen über Dogmatismus und Kritizismus, en: Schellings Werke, ed. M. Schröter, München: C. H. Beck, 1927-1958, S. 285 [= PhBDK]; (Cartas Filosóficas sobre o Dogmatismo e o Criticismo, São Paulo: Ed. Abril Cultural [= CFDC], Primeira Carta, p.180).

16. PhBDK, 285 (CFDC, Primeira Carta, p. 180).

17. Ibidem.

18. Ibidem.

19. Ibidem. Como diz Schelling, no fundo tal idéia se mostra apenas expressão de um querer ("essa ideia [...] quer um Deus"). Nessa medida falta a ela, igualmente, o poder de limitar o mundo, porque aqui o querer mesmo teria que realizar uma operação do tipo: primeiro teria de tomar do mundo, para só então poder dá-lo a Deus. (Cfr. PhBDK, 284-5 - CFDC, Primeira Carta, pp. 179-80). Esta idéia, fundada em solo criticista - enquanto é expressão apenas desse querer - segundo Schelling não representa a vantagem que se esperaria sobre o dogmatismo.

20. Enfim, a questão que permanece é a de "explicar como representações podem coincidir absolutamente com objetos que existem em inteira independência delas". (Cfr. SIT 175) Schelling mantém a ênfase sobre a importância fundamental do estabelecimento positivo (Dogmatismo 
Perfeito) da Filosofia com vistas à possibilidade de considerar filosoficamente a evolução e o contínuo progresso do conhecimento. E por isso é decisiva a abordagem positiva da razão, do contrário faltaria estofo (lastro, apoio) para a investigação da física. Diz Schelling: "Visto que a possibilidade de toda experiência se baseia na aceitação de que as coisas são precisamente como as representamos, por conseguinte, de que sem dúvida conhecemos as coisas como são em si (pois, sem este pressuposto da identidade absoluta do ser e do aparecer, que seria a experiência e para onde se extraviaria, por exemplo, a física?) é idêntica a resolução dessa tarefa à tarefa da filosofia teórica, a qual tem de investigar a possibilidade da experiência". (SIT 156).

21. Carta de Schelling a Hegel (Tübingen, 4 de fev. de 1795), Correspondências, in: G.W.F. HEGEL, Escritos de Juventud, México: FCE, 2003, p. 59. Em correspondência datada de 21 de julho de 1795, é anunciada por Schelling a Hegel a publicação no jornal de Niethammer do seu texto Cartas Filosóficas sobre o Dogmatismo e o Criticismo. (Cfr. Correspondências, p. 62-64) E no contexto da carta de Hegel a Schelling, datada de janeiro de 1795, Hegel afirma: "Se tivesse tempo, trataria de tornar preciso até que ponto, após consolidar a fé moral, nós necessitamos regressivamente da ideia legitimada de Deus", constante ao problema que ocupava, de certo modo, já Schelling no texto Cartas Filosóficas sobre o Dogmatismo e o Criticismo - de considerar "até que ponto se pode transpor da teológica ética à teologia física e com ela operar neste terreno". Cfr. Correspondências, p. 54-56.

22. PhBDK 310 (CFDC, Sexta Carta, p.193).

23. PhBDK 290 (CFDC, Segunda Carta, p. 182).

24. PhBDK 310 (CFDC, Sexta Carta, p. 193).

25. PhBDK 310 (CFDC, Sexta Carta, p. 193).

26. PhBDK 310 (CFDC, Sexta Carta, p. 193).

27. PhBDK 310 (CFDC, Sexta Carta, p. 193).

28. PhBDK 310 (CFDC, Sexta Carta, p. 193).

29. Ora, no dizer de Schelling, o criticismo se mostrou insuficiente na medida em que considerou "a faculdade de conhecer como algo (...) próprio do sujeito, mas não necessário nele". (PhBDK 295 - CFDC, Terceira Carta, p. 185) Enquanto a crítica da mera faculdade de conhecer só conseguira ver "o sujeito na medida em que ele mesmo é o objeto da faculdade de conhecer e, portanto, completamente diferente dela [dessa faculdade]". Sem poder se refazer do erro de "considerar que a faculdade de conhecer é independente do próprio ser do sujeito", a desvantagem do lado do criticismo é patente. Portanto, a ação de síntese tem de ser considerada a partir do ser originário: "tem de [se] aceitar que só chego ao objeto por mim mesmo e que não posso subir nos meus próprios ombros para olhar para além de mim mesmo." PhBDK 296 (CFDC, Quarta Carta, p. 186).

30. A passagem expressa diz assim: "Pois uma lei que não é explicável por nenhuma existência independente dela, que comanda a potência suprema assim como a menor de todas, não tem nenhuma sanção, senão a necessidade." (PhBDK 288 - CFDC, Primeira Carta, p. 181)

31. PhBDK 290 (CFDC, Segunda Carta, p. 182).

32. E, diz Schelling: "Sem dúvida, a um cânon de todos os sistemas pertence também, como parte necessária, a metodologia universal". Em seguida lamenta: "Mas nada de mais triste pode acontecer a uma tal obra do que ver o método que estabelece para todos os sistemas ser tomado pelo próprio sistema". (PhBDK 301 - CFDC, Quinta Carta, p. 188). E adiante expressa: “A Crítica da razão pura não se destina a fundar com exclusividade um sistema qualquer (...). Pelo contrário, destina-se precisamente (...) a deduzir a possibilidade de dois sistemas diretamente opostos um ao outro, a partir da essência da razão, e fundar tanto um sistema do criticismo (pensado em sua perfeição) quanto um sistema, diretamente oposto a esse, do dogmatismo". (PhBDK 302 - CFDC, p. 189). Ou seja, "ela vale para ambos porque vale tanto para o sistema do criticismo quanto para o do dogmatismo, e o criticismo e o dogmatismo nada mais são do que o idealismo e o realismo pensados sistematicamente". (PhBDK 303 - CFDC, p.189). Historicamente, a mútua oposição entre criticismo e dogmatismo levara somente à anulação de um pelo outro, sem a conquista de uma 
posição intermediária, de conciliação incondicional. A intenção schellinguiana se dirige para esse fim.

33. PhBDK 293 (CFDC, Terceira Carta, p. 184).

34. PhBDK 304 (CFDC, Quinta Carta, p. 189). No dizer de Schelling, enquanto o método dos postulados práticos não podia pertencer com exclusividade a um dos sistemas; e enquanto há dois sistemas inteiramente opostos um a outro, o coroamento do dogmatismo perfeito se dá como se levantou - ainda que menos explicitamente - da Crítica da Faculdade do juízo, o Imperativo Técnico, ao modo da solução da Antinomia da faculdade do juízo teleológico (\$§ 69-78). Na Terceira Crítica, tratando do conflito da antinomia no âmbito da faculdade do juízo reflexionante, Kant afirmou que "o entendimento, que não (...) consegue igualar o passo" da razão (Kritik der Urteilkraft, [= KdU], em: Cfr. Immanuel Kant Werkausgabe: in zwölf Bänden. Hrsg, Wilhelm Weischedel. Frankfurt a. M.: Suhrkamp, 1968, Bd. X, 339 (Crítica da faculdade do juízo [= CFJ], tr. V. ROHDEN, Rio de Janeiro: Ed. Forense Universitária, 1995, p. 242), não tem como comportar o espaço que essa última tem à solução de questões que geram impasses. Sabe-se, no entanto, que nessa esfera nem a razão, nem o entendimento solucionam a antinomia, porque num domínio onde as questões que caem não exigem ser determinadas, o apaziguamento do conflito unicamente pode ser atribuído ao título de uma validade apenas subjetiva, a saber, a da própria faculdade de juízo, de modo necessário. É a faculdade do juízo que conduz os conflitos à unidade na ideia (aos conceitos da razão), contornando a ilusão de uma possível determinação e conhecimento nessa área. Enquanto tal as ideias transcendentais são figuras do pensar que exigem estritamente tal uso meramente regulativo. Pode-se dizer que as ideias transcendentais de Deus, liberdade e imortalidade representam um substrato antropológico perene, cujo destino é aparecer como questão em dados momentos da vivência humana, mas cuja abordagem crítica de tal aparecer - como na expectativa de um surgimento regular - requer, por sua vez, a compreensão de que o que tais questões exigem é o mesmo que pode ser fornecido a elas: somente uma resposta dada enquanto regra, regra para a reflexão.

35. PhBDK 310 (CFDC, Sexta Carta, p. 193). Continua Schelling: "Para o filósofo crítico, mais concebível do que qualquer outra coisa é o Absoluto em nós. Mas, como saímos do Absoluto, para opor algo a nós pura e simplesmente, é inconcebível [a ele]".

36. PhBDK 306 (CFDC, Quinta Carta, pp. 190-1).

37. PhBDK 306 (CFDC, Quinta Carta, p. 190).

38. PhBDK 302 (CFDC, Quinta Carta, p. 189).

39. À pergunta: quais são os limites da intuição? - pode-se responder de dois modos distintos. Primeiro: se se a pensa como matéria (passividade), à qual as faculdades de conhecimento têm de se debruçar, encontramo-la como aquela noção desenvolvida e mantida com ênfase por Kant; e se se a pensa, por outro lado, como intuição formal, como aquela atividade originária devida à faculdade de Imaginação transcendental, então se encontra a noção que Schelling quer enfatizar. Para realçar, por analogia, a legitimidade do elemento dogmático perfeito mediante a noção de uma antecipação entreaberta, pode-se completar desde o ângulo em que o texto Cartas pressupõe isso, a saber, de que aqui "não se trata de uma obra de virtuosismo, onde se reencontra no final apenas aquilo que inicialmente - e bem astutamente - havia já sido preparado para ser encontrado" (PhBDK 312 - CFDC, Sexta Carta, p. 194), porque "necessariamente um sistema do saber [...] tem de adquirir realidade [...] por uma faculdade prática, [...] por uma faculdade produtiva, realizadora, [...] pelo agir". (PhBDK 300 - CFDC, Quinta Carta, p. 190) ou, como vimos chamando aqui, por uma faculdade técnica.

40. PhBDK 296 (CFDC, Quarta Carta, p. 185).

41. À título informativo, quando publicadas no Philosophisches Journal, as cartas traziam o título Cartas filosóficas sobre o Dogmaticismo e o Criticismo e, na reunião delas ao volume Escritos Filosóficos, fora corrigido e convertido dogmaticismo para dogmatismo. Essa não é uma nuance despropositada, sem uma finalidade específica no contexto de Cartas. No Prefácio da $2^{\mathrm{a}}$ ed. da 
Crítica da razão pura Kant distinguira entre o dogmatismo autêntico e o dogmatismo cego, dizendo: “A Crítica não se opõe ao procedimento dogmático da razão no seu conhecimento puro como ciência (pois esta tem que ser sempre dogmática, isto é, provando rigorosamente a partir de princípios seguros a priori), mas sim ao dogmatismo, isto é, à pretensão de progredir apenas com um conhecimento puro a partir de conceitos (o filosófico) segundo princípios há tempo usados pela razão, sem se indagar, contudo, de que modo e com que direito chegou a eles" (KrV XXXV - CrP 30).

42. $\mathrm{KrV}$ B 519 (CrP 437).

43. O caráter monocromático trazido nessa exposição da doutrina do Idealismo transcendental é enriquecido de nuanças quando Kant realiza a distinção entre fenômeno e noumeno, no capítulo da Crítica da razão pura, intitulado Do Princípio da distinção de todos os objetos em geral em fenômeno e noumeno. (Cfr. KrV B 295-315 - CrP 257-273).

44. A descoberta por F. Rosenzweig, em 1917, de uma folha manuscrita (frente e verso) oriunda do final do século XVIII, cuja composição remetia à autoria conjunta de três jovens ex-estudantes de teologia do Tübinger Stift (Hegel, Schelling e Hölderlin) fora publicada naquele ano sob o título de 0 mais antigo Programa de Sistema do Idealismo alemão (Das Älteste Systemprogramm des Deutschen Idealismus), cuja data de redação teria sido estabelecida entre março e agosto de 1796. À parte da celeuma entre os especialistas para determinar sua exata autoria (que demonstra pelos estudos caligráficos trazer a letra de Hegel, o estilo de Schelling, mas os componentes poéticos e idéias de Hölderlin), a frase que mais instigara o debate em torno do texto, e parece resumir a força do que será o projeto filosófico do Idealismo alemão, é a sentença que afirma: "Somente o que é objeto da liberdade chama-se ideia". Cfr. R.R. TORRES FILHo, Schelling, São Paulo: Abril Cultural (Col. Os Pensadores), 1974, p. 40. A corrente de estudos denominada de Idealismo alemão nasce da conjunção do kantismo e espinosismo, como escolas que, no debate fichtiano e schellinguiano, inicialmente exprimirão a oposição entre Criticismo (Idealismo) e Dogmatismo (Realismo). (Cfr. Documento: Escritos Filosóficos de Hölderlin, in: K. H. ROSENFIELD (Org.), Filosofia e literatura: o trágico, Rio de Janeiro: Jorge Zahar, 2001 (Filosofia politica-serie III,n.1), pp. 163-174.

45. GA I/4, 219 ZE.

\section{RESUMOS}

Fichte developed the foundations of transcendental reason according to Kant's transcendental Idealism. In articles of 1797, the First and the Second Introduction to the 'Wissenschaftslehre', Fichte refuted the dogmatic and empiricist perspectives, which were developed as continuers of Kantian criticism. Schelling also drafted the refutation of dogmatism and criticism in the text of 1795, 'Philosophischen Briefen über Dogmatismus und Kritizismus'. From a different refutation strategy, each philosopher settled his own conceptual system. The following we show the outlines of these strategies, pointing what distinguishes each of the approaches.

\section{ÍNDICE}

Keywords: transcendental philosophy, thing-in-itself, transcendental idealism, dogmatism 
AUTOR

LUCIANO CARLOS UTTEICH

Universidade Estadual do Oeste do Paraná 